www.jmscr.igmpublication.org Impact Factor 5.244

Index Copernicus Value: 5.88 ISSN (e)-2347-176x ISSN (p) 2455-0450 crossref DOI:_http://dx.doi.org/10.18535/jmscr/v4i6.29

\title{
Interesting Cause of Obstructive Jaundice Diagnosed by Endoscopic Ultrasound
}

\author{
Authors \\ Dhaval Choksi ${ }^{1}$, Ruchir Patel ${ }^{2}$, Prateik Poddar ${ }^{3}$, Kaivan Shah ${ }^{4}$, Meghraj Ingle ${ }^{5}$, \\ Prabha Sawant ${ }^{6}$ \\ ${ }^{1}$ Department of Gastroenterology, Lokmanya Tilak Municipal Medical College and General Hospital, \\ Sion, Mumbai, India, Email: dhavalrchoksi@gmail.com \\ ${ }^{2}$ Department of Gastroenterology, Lokmanya Tilak Municipal Medical College and General Hospital, \\ Sion, Mumbai, India Email: Ruchir.cn@gmail.com \\ ${ }^{3}$ Department of Gastroenterology, Lokmanya Tilak Municipal Medical College and General Hospital, \\ Sion, Mumbai, India, Email: prateikpoddar@gmail.com \\ ${ }^{4}$ Department of Gastroenterology, Lokmanya Tilak Municipal Medical College and General Hospital, \\ Sion, Mumbai, India, Email: Drkaivanshah26@gmail.com \\ ${ }^{5}$ Department of Gastroenterology, Lokmanya Tilak Municipal Medical College and General Hospital, \\ Sion, Mumbai, India, Email: drmeghraj@gmail.com \\ ${ }^{6}$ Department of Gastroenterology, Lokmanya Tilak Municipal Medical College and General Hospital, \\ Sion, Mumbai, India, Email: prabhasawant@hotmail.com \\ Corresponding Author \\ Dhaval Choksi \\ Department of Gastroenterology, \\ Lokmanya Tilak Municipal Medical College and General Hospital, Sion, Mumbai, India \\ Email -dhavalrchoksi@gmail.com, Phone - +91-9820873144, / +91-9850084244
}

\begin{abstract}
Hepatobiliaryascariasis is a common problem in tropical countries including India. It can present with intermittent symptoms and fluctuating imaging results and blood parameters as the worm migrates within the gastrointestinal tract. Patient can present with biliary colic, obstructive jaundice, ascending cholangitis, acalculouscholecystitis or acute pancreatitis. We present a case of obstructive jaundice in a 37 years old female, post cholecystectomy status. Patients abdominal ultrasound was apparently normal 1 week before jaundice, which was done for abdominal pain. Biliary ascariasis was diagnosed using endoscopic ultrasound (EUS). A live adult ascaris was removed from common bile duct (CBD) by endoscopic retrograde cholangiopancreatography (ERCP).
\end{abstract}

KEYWORDS: Ascarislumbricoides, common bile duct, Endoscopic ultrasound, Endoscopic retrograde, cholangiopancreatography hepatobiliary, obstructive jaundice. 


\section{INTRODUCTION}

Hepatobiliaryascariasis is a common problem in tropical countries including India. It can present with intermittent symptoms and fluctuating imaging results and blood parameters as the worm migrates within the gastrointestinal tract. We present a case of obstructive jaundice in a 37 years old female, post cholecystectomy patient with normal ultrasound abdomen, diagnosed with biliary ascariasis on endoscopic ultrasound, which was removed by endoscopic retrograde cholangiopancreatography.

\section{CASE REPORT}

A 37 years old female came with complaints of abdominal pain in right hypochondriumsince seven days. Her ultrasound abdomen done in a private nursing home showed grade I fatty liver, periportal echogenicity, mild splenomegaly, post cholecystectomy status and dilated CBD. She was treated symptomatically. However, there was no relief in pain. So the patient was referred to our centre. Patient also gave history of fever and jaundice since 3 days, associated with 3 episodes of vomiting. There was significant past history of obstructive jaundice due to choledocholithiasis five months back. Patient had undergone endoscopic retrograde cholangiopancreatography followed by cholecystectomy for the same.

On examination she was febrile, icteric and had right hypochondriac and epigastric tenderness. Rest of the examination was normal.

Her hemoglobin was $12.2 \mathrm{gm} / \mathrm{dl}$. WBC 15500/microlit. Platelet count 1.93 lakh/microlit. Total bilirubin $-2.5 \mathrm{mg} / \mathrm{dl}(0-1.2)$, direct $-0.8(0$ - 0.3), AST - 408 (0 - $40 \mathrm{IU} / \mathrm{L})$, ALT - 688 ( 0 $40 \mathrm{IU} / \mathrm{L})$, ALP - $688(80-306)$, Rest of the blood tests like renal function test, electrolytes, prothombin time, amylase, albumin were normal.

As the patient had history and bicchemical parameters suggestive of obstructive jaundice with cholangitis we did her endoscopic ultrasound examination. Her endoscopic ultrasound revealed a motile linear echogenic structure in the common bile duct. There was no acoustic shadow from this echogenic structure (fig. 1). Patient then underwent ERCP (fig. 2) and a live adult worm was retrieved from the CBD (fig $3 \& 4$ ). The worm was identified as Ascarislumbricoides. Antihelminths were subsequently given to the patient. Patient improved with the treatment and was discharged after 3 days. The liver function test normalized after ERCP.

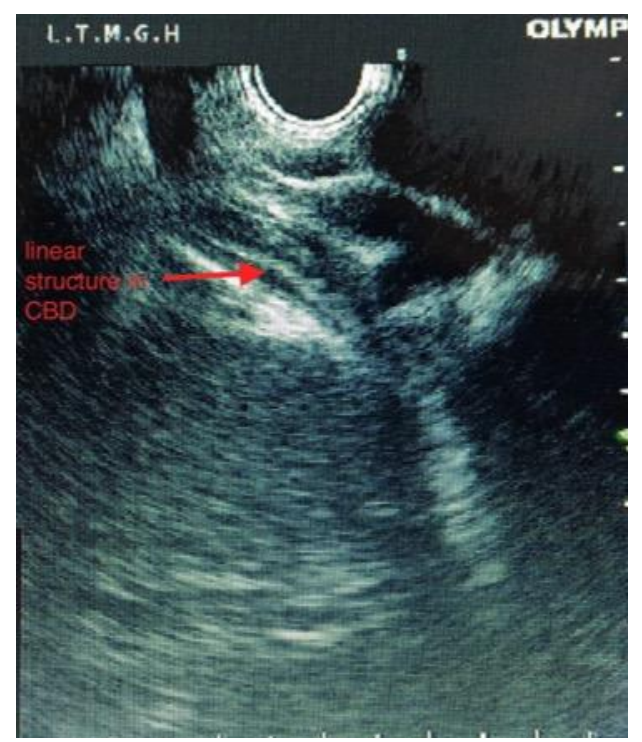

Figure 1 - EUS image showing a linear filling defect in the common bile duct (CBD).

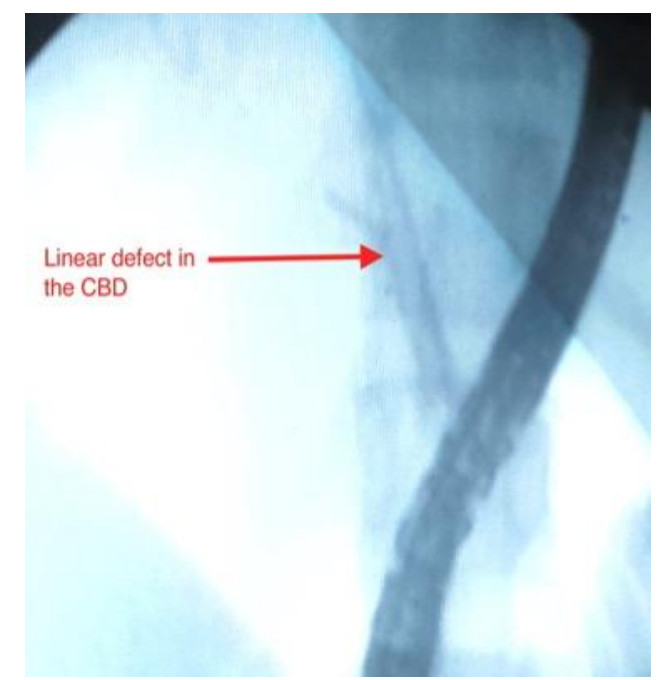

Figure 2 - Cholangiogram showing linear filling defect in the CBD. 


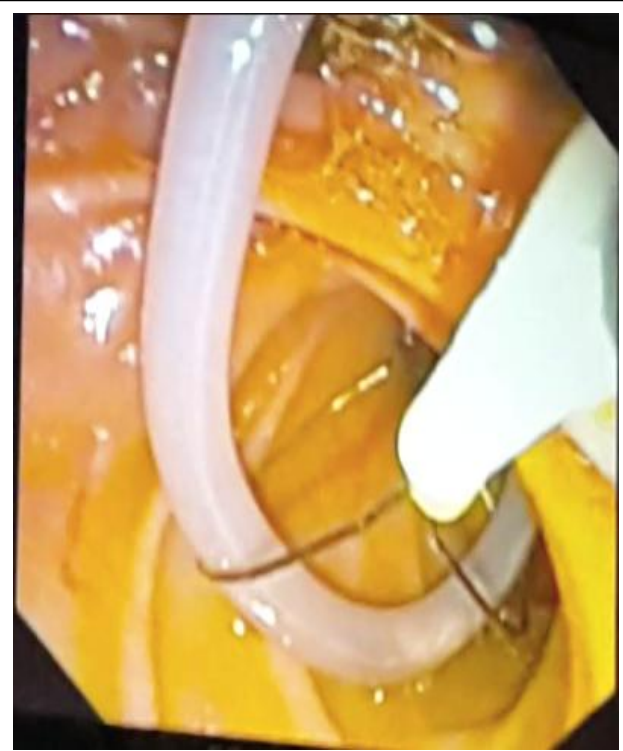

Figure 3 - CBD worm with one end in the duodenum

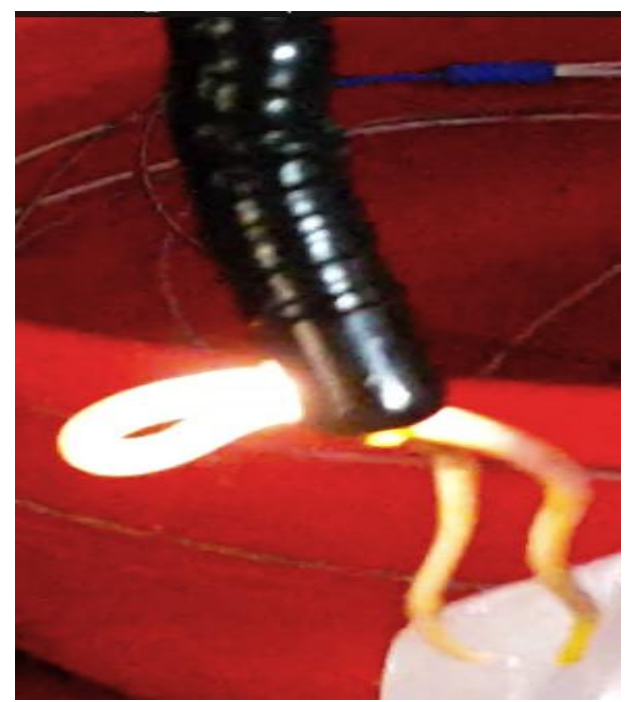

Figure 4 - CBD worm removed by ERCP

\section{DISCUSSION}

Hepatobiliaryascariasis is a common problem in places with poor sanitation. ${ }^{1}$ Diagnosis requires a high index of suspicion in patients residing in endemic areas. Hepatobiliaryascariasis is a common complication of endoscopic sphincterotomy. Gupta et al. reported four cases of biliary ascariasis among 273 cases with post-endoscopic sphincterotomy for choledocholithiasis in India with interval period of 2-24 weeks. ${ }^{2}$

Abdominal ultrasonography is the first modality for evaluation of such patients. It can diagnose biliary ascariasis in majority (upto $85 \%$ ) of cases. However as the live adult worm is highly motile one can get fluctuating imaging results and blood parameters. ${ }^{1}$ The characteristic sonographic features of worm in the common bile duct is, long, linear, parallel echogenic strip, usually without acoustic shadowing. ${ }^{3}$ Endoscopic ultrasonography is now considered the most sensitive method for evaluation of a dilated bile duct and can increase the sensitivity of diagnosis of biliary ascariasis. ${ }^{4}$

Endoscopic retrograde cholangiopancreatography, is considered the gold standard for management of biliary ascariasis. It should however be reserved for therapeutic rather than diagnostic use because papillotomy can lead to reentry of the worm into the common bile duct. ${ }^{5}$ Management includes removal by gently holding the ascaris with a basket. The entry of the worm inside the bile duct generally keeps the ampulla patulous and it is possible to put in the basket inside the common bile duct without sphincterotomy. Only if basket cannot be introduced inside common bile duct is the sphincterotomy done to facilitate the removal of worm. ${ }^{5}$ Follow-up treatment by antihelminthetics is recommended to prevent reentry of any other ascaris residing in the small bowel. Our patient had the risk factors like residing in endemic area and history of sphincterotomy. The unique feature was it was diagnosed by EUS even though abdominal ultrasoundwas normal.

\section{CONCLUSIONS}

Residence in endemic region and papillotomyare risk factor for entry of worm in the common bile duct and subsequent complications like jaundice and cholangitis. EUS can help diagnose such cases even in inconclusive transabdominal ultrasound. ERCP is the treatment of choice with good success.

\section{ACKNOWLEDGEMENT}

We acknowledge the help of department of microbiology in identifying the worm.

Financial disclosure - None

Conflict of interest - None

Consent - Informed consent was obtained from the patient. 


\section{REFERENCES}

1. David EE. Sleisenger and Fordtran's Gastrointestinal and Liver disease, $10^{\text {th }}$ edition, Elsevier 2014.

2. Gupta R, et al. Biliary ascariasis complicating endoscopic sphincterotomy for choledocholithiasis in India. J Gastroenterol Hepatol. 1998;13:1072-1073

3. Mijandrušič-Sinčič, B., et al. Acute pancreatitis caused by Ascarislumbricoides: a case report. Gastrointest Endosc. 2008; 67: 541-542

4. Sharma, M. and Garg, S. Endoscopic ultrasound for ascaris in common bile duct. Endoscopy. 2009;41: E209-E210

5. Sandouk, F. et al. Pancreatic-biliary ascariasis: experience of 300 cases. Am J Gastroenterol. 1997; 2: 2264-2267 